\title{
Alcohol Dependence: A Major Health and Socio-Economic Problem
} Israel Oluwasegun Ayenigbara*

Department of Human Kinetics and Health Education, University of Ibadan, Nigeria

*Corresponding author: Israel Oluwasegun Ayenigbara, Department of Human Kinetics and Health Education, University of Ibadan, Nigeria, Tel: +08139177538; Email: histrealite2647@gmail.com

Received date: September 03, 2018; Accepted date: September 14, 2018; Published date: September 20, 2018

Copyright: ( 2018 Ayenigbara IO. This is an open-access article distributed under the terms of the Creative Commons Attribution License, which permits unrestricted use, distribution, and reproduction in any medium, provided the original author and source are credited.

\begin{abstract}
Alcohol dependence is a major health problem worldwide; about 3.3 million net deaths were caused by drinking of alcohol. This paper discuses alcohol dependence as a major health and socio-economic problem. It is a position paper in which the disadvantages of alcohol were elaborately discussed with emphasis on its health and socioeconomic consequences. Preventive measures were provided under; school based intervention, community engagement, family intervention, work place intervention and regulation of Alcohol usage. It was therefore concluded that heavy drinking affects not only on the drinkers health, but also his economy, Job, social interaction with people and school performance. Hence, it was recommended that alcohol consumption should be reduced to the barest minimum or not consumed at all as all alcohol consumption carries some risk and no level of alcohol is safe to drink for women in pregnancy.
\end{abstract}

Keywords: Alcohol dependence; Health; Socio-economic problem; Prevention

\section{Introduction}

Frequently drinking of much alcohol is harmful to health, this is evident by the health consequences that go along with it. As such, Alcohol has an impact on everybody system. How much alcohol a person drinks, genetic factors, gender, body mass, and general state of health all influence how a person's health responds to chronic heavy drinking.

Alcohol dependence also called Alcoholism is a continuous problem that makes one craves for alcohol and one has no control over his or her drinking. Alcoholism affects the physical, mental and social health, thereby making drinkers to have problems with family, friends, and where they work. Dependence on alcohol makes one feel that he or she cannot do their daily activities well without consumption of alcohol. If one drinks heavily, the person has the tendency to keep increasing the amount he drinks because tolerance to alcohol will develop [1]. Tolerance can be defined as a physiological response one have to any drug. For example, the higher the consumption of alcohol, the more the consumption one needs to consume to have similar effect.

Dependence on Alcohol is a major health problem worldwide; it affects virtually all age groups without any regard for status or gender. According to CDC [2], there is a mortality rate of about 88,000 people (approximately 62,000 men and 26,000 women) from alcohol-related causes yearly. On the global level, In 2012, there were 3.3 million mortality, were linked to alcohol consumption [3] and WHO [3], the World Health Organization reported that alcohol contributed to more than 200 diseases and injury- related health conditions. In 2012, 5.1 percent of diseases and injury worldwide was linked to alcohol drinking [3]. Also, globally, misuse of Alcohol was ranked fifth as the leading risk factor for premature death and disability in 2010, among people between the ages of 15 and 49, it was ranked first [3]. For the age groups of 20-39 years, 25 percent of the total deaths are linked to alcohol [4].
The aforementioned statistics on Alcoholism are frightening and one will begin to wonder why such preventable disease could be causing so much havoc. In this paper, the authors reviewed the latest literatures on the health and socio-economic problems of Alcohol dependence; with the hope that it will to deter people from drinking, its preventive measures were also discussed.

\section{Alcohol dependency}

When a person has a dependency on alcohol, they feel continuous cravings for drinking, and may suffer light to severe withdrawal symptoms if they stop. They also feel the need to drink ever-increasing amounts in order to get a "buzz" or get drunk. Even with the realization that drinking is affecting their health or their relationship with others, they will still drink [5]. With the DSM-IV criteria for alcohol dependence, formed by American Psychiatric Association [6], at least three out of seven of the following criteria must have manifested during a 12-month period to affirm that one is Alcohol dependent:

- Tolerance.

- Withdrawal symptoms.

- Usage of Alcohol in larger quantity or for longer periods not expected.

- The urge or futile efforts to reduce the usage of alcohol.

- Larger Time is used getting alcohol or recovering from it's side effects.

- Daily activities are given up or reduced because of alcohol use.

- Usage is not stopped even with knowledge of alcohol-related harm which could be physical or psychological.

\section{Signs and symptoms of alcohol dependency}

The following According to Drinkaware [1], are some signs to lookout for that may suggest one is becoming dependent on alcohol:

- Being perturbed about where the next drink is coming from and planning ones activities around alcohol. 
- The strong urge to drink and it is difficult to stop.

- Waking up because of Alcohol or feeling the need to drink early in the morning.

- Being disturbed, alcohol-related depression and suicidal feelings. All these develop because frequent, much alcohol consumption interferes with neurotransmitters in the brains.

- Problems from withdrawal symptoms e.g., sweating, shaking and weakness, which goes away once one drink alcohol.

\section{Health problems of alcohol dependence}

Alcoholism through various studies and researches has been confirmed to cause or be a lead way to different diseases and injuries. Some of the diseases and injuries impacted by alcohol consumption are as follows:

Neuropsychiatric conditions: Alcohol Use Disorders (AUDs) are the most important neuropsychiatric conditions caused by alcohol consumption. According to Samokhvalov et al. [7] Epilepsy is another disease impacted by alcohol, over and above withdrawal-induced seizures. Kessler [8]; Boden et al. [9] opined that Alcohol consumption is associated with many other neuropsychiatric conditions; examples are depression or anxiety disorders.

Gastrointestinal diseases: Liver cirrhosis [7], and pancreatitis (both acute and chronic; [10] are causally linked to alcohol consumption. Higher levels of alcohol consumption create an exponential increase in risk. The impact of alcohol is so important that for both disease categories there are subcategories which are labeled as "alcoholic" or "alcohol-induced" in the ICD.

Cancers: Alcohol consumption has been identified as carcinogenic for the following cancer categories [11] cancer of the mouth, nasopharynx, other pharynx and oropharynx, laryngeal cancer, esophageal cancer, colon and rectum cancer, liver cancer and female breast cancer. In addition, alcohol consumption is likely to cause pancreatic cancer. The higher the consumption, the greater the risk for these cancers, with consumption as low as one drink per day causing significantly increased risk for some cancers, such as female breast cancer [12-14].

Intentional injuries: Alcohol consumption, especially heavy drinking, has been causally linked to suicide and violence $[15,16]$.

Unintentional injuries: Almost all categories of unintentional injuries are impacted by alcohol consumption. The effect is strongly linked to the alcohol concentration in the blood and the resulting effects on psychomotor abilities. Higher levels of alcohol consumption create an exponential increase in risk [17].

Cardiovascular diseases (CVD): The relationship between alcohol consumption and cardiovascular diseases is complex. The beneficial cardio-protective effect of relatively low levels of drinking for ischemic heart disease and ischemic stroke disappears with heavy drinking occasions. Moreover, alcohol consumption has detrimental effects on hypertension, atrial fibrillation and hemorrhagic stroke, regardless of the drinking pattern [18]. Fetal Alcohol Syndrome (FAS) and preterm birth complications: Alcohol consumption by an expectant mother may cause these conditions that are detrimental to the health of a newborn infant [19].

Diabetes mellitus: A dual relationship exists, whereby a low-risk pattern of drinking may be beneficial while heavy drinking is detrimental.
Infectious diseases: Harmful use of alcohol weakens the immune system thus enabling development of pneumonia and tuberculosis. This effect is markedly more pronounced when associated with heavy drinking, and there may be a threshold effect, meaning that disease symptoms manifest mainly if a person drinks above a certain level of heavy drinking [20-24].

\section{Socio-economic problems of alcohol dependence}

Alcohol consumption is usually linked with socioeconomic consequences; these socioeconomic consequences are tied up with other people's feelings or thoughts for example, where use of alcohol is prohibited because of religious or cultural reasons, drinking at all will be negatively judged by others. Also in societies and communities where drinking is thoroughly integrated into daily life and it seen as way of socializing, there are limits of acceptable drinking behavior, whether in terms of a specific drinking event or a specific pattern of drinking [9]. When an individual crosses culture-specific boundaries in relation to alcohol consumption, he or she may experience socioeconomic problems such as loss of earnings, unemployment or family problems, stigma and barriers to accessing health care. Alcohol is typically a valued commodity, which means that drinking usually uses resources (money) which would otherwise be available for other purposes. According to (Schmidt et al. [22], De Silva et al. [23]). Where earnings are low, heavy drinking may further impoverish the drinker, the drinker's family, or a whole community, thus increasing health or social harm.

Intoxication, dependence or alcohol withdrawal states can result in poor performance in major social roles-in functioning at work, in parenting, in relationship and friendship roles. Both the drinker and others may be affected by the consequences, such as job or productivity loss, break-up and dysfunction in family life, including domestic violence. This in turn can result in harm to physical or mental health, caused by the role functioning impairment itself, others' reactions to the impairment, or both [22]. The reputational drinking history of an individual, i.e., how the pattern of drinking is interpreted by others, is crucial in social judgments, both those made in the moment and in the longer term.

There is a clear tendency in many cultures to marginalize and socially exclude habitually intoxicated persons and their families, even more so than "dirty or unkempt" persons [25]. One direct path by which marginalization can affect health status is through diminished access to good health care. In several surveys around the world, respondents felt that heavy alcohol users should receive less priority in health care. Often the justification given is the belief that the users' behavior contributed to their own illness [25]. More worryingly, studies on health services show that the care given is likely to be inferior, or the access to health care worsened, if the patient is seen as a run-down drinker or a similarly degraded status [26-29]. Given that access to good health care is expected to affect health status, this is a major concern both at the individual and at the societal level.

\section{Prevention of Alcoholism}

Effective Alcohol prevention programs include the following elements:

\section{Interventions from schools}

School is an important part of most young people's lives and, as such, school is a strategic place for Alcohol prevention and 
intervention efforts. The following are the preventive guidelines to be followed in schools:

- Change the saying that everybody is drinking.

- Impact in youth how to say no to alcohol.

- Adopt new teaching methods such as small-group activities, role plays, and same-age leaders.

- Involvement of parents and other segments of the community.

- Teach topics over the years to reinforce prevention messages.

- As a school administrator, Provision of training and support for teachers and students is important.

\section{Communities engagement}

School-based interventions simply cannot address every situation. However, community-based efforts in conjunction with school-based prevention curriculum can help reduce alcohol use among youth hand young adults [30]. Such efforts include limiting alcohol sales to underage, increasing enforcement of underage drinking laws, and changing alcohol policies at community events, as well as increasing public awareness about the problems associated with underage drinking.

\section{Family interventions}

Family factors are strong determinants whether a young person will start to use alcohol [31]. e.g., lack of a positive parent-child relationship or a family history of alcohol problems both can increase risk. On the other hand, a child who has strong family bonds with his or her parents and who has parents who are actively involved in his or her life often is less likely to engage in underage drinking, Because family influences are so pivotal in shaping adolescent problem behaviors, programs that focus on parenting practices parent-child communication, parent-child bonding, and effective family management-can reduce problem behaviors in children and adolescents. Family-focused interventions can be successful both for general populations and for families with adolescents who exhibit more serious delinquent behaviors [32].

\section{Interventions in the workplace}

Because most adults are employed, workplace programs can potentially reach audiences and populations that otherwise would not have access to a prevention program. Workplace prevention programs can help address some of the factors that may accompany abusive drinking. For example, lifestyle campaigns have shown promise in encouraging workers to ease stress, improve nutrition and exercise, and reduce risky behaviors such as drinking, smoking, and drug use. Programs that promote social support and worker peer referral to substance abuse or other treatment program scan are beneficial. Such campaigns also may include brief interventions that involve personal assessment of an individual's drinking rate sand related problems [33].

\section{Prevention in the military}

Military personnel ages 18 to 35 have rates of heavy drinking about 60 percent higher than civilians in those age-groups [34]. Recognizing these problems have led to efforts to reduce the availability of alcohol in communities with service bases. Such approaches include asking for identification checks, making sure alcohol retailers near a base do not serve minors, increasing the number and frequency of Driving Under the Influence (DUI) checks, fostering community-based awareness, and supporting media campaigns to reduce drinking and promote alternative activities that do not include alcohol (e.g., sports).

\section{Policy and laws about alcohol}

Public policy often addresses the circumstances surrounding abusive drinking by particular groups. Such policies also can help prevent the adverse consequences of alcohol consumption in wider audiences, and on a larger scale, than any other category of interventions. Changes to laws and policies related to alcohol's availability and the consequences of its use lead to significant gains in public health. Such laws include; raising the minimum legal drinking age to 21 ; and enacting the zero-tolerance law for driver's younger than 21 , who are not permitted to have any alcohol in their systems while driving [35].

\section{Effects of prices on alcohol use and its consequences}

Increasing the price of alcoholic beverages (for example, through raising taxes) leads to decreased consumption, both in the general population and in certain high-risk groups, such as heavier drinkers and adolescents and young adults [36]. Price increases can help reduce the risk of adverse consequences of alcohol consumption and abuse, including drinking and driving, alcohol-involved crimes, liver cirrhosis and other alcohol-related mortality, risky sexual behavior and its consequences, and poor school performance among youth.

\section{Additional alcohol policies}

Other policy areas offer more tools to address alcohol-related problems in youth and adults, and community-based prevention program soften make these their focus. Such areas include laws and regulations related to the minimum legal drinking age and sales to underage youth; privatization or monopolization of alcohol control systems (production, distribution, or sales); monitoring of alcohol outlet densities; and limits on the hours and days of alcohol sales. Restrictions in these areas make alcohol less available and have been effective in reducing alcohol abuse and related problems, as noted in major policy reviews [37-61].

\section{Conclusion}

It was concluded after review that drinking too much alcohol can take a heavy toll, not only on a person's health but also on his or her family relationships, economic, Job, social interaction with people and school performance.

\section{Recommendations}

Based on this review, it was recommended that alcohol consumption should be reduced to the barest minimum or not consumed at all as all alcohol consumption carries some risk and no level of alcohol is safe to drink for women in pregnancy.

\section{References}

1. Drinkaware (2016) Alcoholism: signs, symptoms and treatment. Retrieved 2nd February, 2018.

2. Center for Diseases Control and Prevention (2010) Alcohol and Public Health: Alcohol-Related Disease Impact (ARDI). Retrieved June 12, 2018.

3. World Health Organization (2014) Global Status Report on Alcohol and Health, p: 14 . 
4. World Health Organization (2015) Alcohol.

5. Searidge (2016) How Alcohol Can Affect You. Retrieved 2nd February, 2018.

6. American Psychiatric Association (1994) Diagnostic and statistical manual of mental disorders. Washington, Am Psychiatr Assoc, pp: 143-146.

7. Rehm J, Taylor B, Mohapatra S, Irving H, Baliunas D, et al. (2010) Alcohol as a risk factor for liver cirrhosis: a systematic review and metaanalysis. Drug Alcohol Rev 29: 437-445.

8. Kessler RC (2004) The epidemiology of dual diagnosis. Biol Psychiatr 56: 730-737.

9. Boden JM, Fergusson DM (2011) Alcohol and depression. Addiction 106: 906-914.

10. Irving HM, Samokhvalov AV, Rehm J (2009) Alcohol as a risk factor for pancreatitis. A systematic review and meta-analysis. JOP 10: 387-392.

11. International Agency for Research on Cancer (2012) A Review of Human Carcinogens: Personal Habits and Indoor Combustions.

12. Seitz HK, Pelucchi C, Bagnardi V, La Vecchia C (2012) Epidemiology and pathophysiology of alcohol and breast cancer: Update 2012. Alcohol and Alcoholism 47: 204-212.

13. Shield KD, Parry C, Rehm J (2013) Chronic diseases and condition related to alcohol use. Alcohol Research Current Reviews 35: 155-171.

14. Cherpitel CJ (2013) Focus on: The burden of alcohol use-trauma and emergency outcomes. Alcohol Res: Current Reviews 35: 150.

15. Macdonald S, Greer A, Brubacher J, Cherpitel C, Stockwell T, et al. (2013) Alcohol consumption and injury. Alcohol: science, policy and public health. Oxford: Oxford University Press.

16. Taylor B, Irving HM, Kanteres F, Room R, Borges G, et al. (2010) The more you drink, the harder you fall: A systematic review and metaanalysis of how acute alcohol consumption and injury or collision risk increase together. Drug Alcohol Depend 110: 108-116.

17. Roerecke M, Rehm J (2012) Alcohol intake revisited: risks and benefits. Curr Atheroscler Rep 14: 556-562.

18. Foltran F, Gregori D, Franchin L, Verduci E, Giovannini M (2011) Effect of alcohol consumption in prenatal life, childhood, and adolescence on child development. Nutr Rev 69: 642-659.

19. Lönnroth K, Williams B, Stadlin S, Jaramillo E, Dye C (2008) Alcohol use as a risk factor for tuberculosis-a systematic review. BMC Public Health 8: 289.

20. Bennett LA, Janca A, Grant BF, Sartorius N (1993) Boundaries between normal and pathological drinking: A cross-cultural comparison. Alcohol Health Res World 17: 190.

21. Schmidt LA, Mäkelä P, Rehm J, Room R (2010) Alcohol: equity and social determinants. Equity, Social Determinants and Public Health Programmes, p: 30 .

22. De Silva V, Samarasinghe D, Hanwella R (2011) Association between concurrent alcohol and tobacco use and poverty. Drug Alcohol Rev. 30: 69-73.

23. Room R, Rehm J, Trotter RT, Paglia A, Üstün TB (2001) Cross-cultural views on stigma, valuation, parity and societal attitudes towards disability. In: Üstün TB eds., Disability and culture: universalism and diversity. Seattle: Hofgrebe \& Huber, pp: 247-291.

24. Olsen JA, Richardson J, Dolan P, Menzel P (2003) The moral relevance of personal Characteristics in setting health care priorities. Soc Sci Med 57: 1163-1172.

25. Sudnow D (1967) Dead on arrival. Transaction 5: 36-43

26. Santana PM (1980) Doctors and dirty work: the case of alcoholism. Sociol Health Illness 2: 24-47.

27. Santana P (2002) Poverty, social exclusion and health in Portugal. Soc Sci Med 55: 33-45.

28. Mitchell AJ, Malone D, Doebbeling CC (2009) Quality of medical care for people with and without comorbid mental illness and substance misuse: systematic review of comparative studies. Br J Psychiatry 194: 491-499.
29. Fagan AA, Spoth JD, Catalano RF (2011) Engaging communities to prevent underage drinking. Alcohol Research \& Health 34: 167-174.

30. Hawkins JD, Oesterle S, Brown EC (2009) Results of a type 2 translational research trials to prevent adolescent drug use and delinquency: A test of Communities That Care. Archives of Paediatrics \& Adolescent Medicine 163: 789-798.

31. Spoth RL, Schainker LM, Hiller-Sturmhöefel S (2011) Translating familyfocused prevention science into public health impact: Illustrations from partnership-based research. Alcohol Research \& Health 34: 188-203.

32. Ames GM, Bennett JB (2011) Prevention interventions of alcohol problems in The work place: A review and guiding framework. Alcohol Research \& Health 34: 175-187.

33. Bray J, Mills M, Bray LM (2009) Evaluating Web-based training for employee assistance program counsellors on the use of screening and brief intervention for at-risk alcohol use. Journal of Workplace Behavioral Health 24: 307-319.

34. Voas RB, Fell JC (2011) Preventing impaired driving opportunities and problems. Alcohol Research \& Health 34: 225-235.

35. Xu X, Chaloupka FJ (2011) The effects of prices on alcohol use and its consequences. Alcohol Research \& Health 34: 236.

36. Anderson P, Chisholm D, Fuhr DC (2009) Effectiveness and costeffectiveness of Policies and programmes to reduce the harm caused by alcohol. Lancet 373: 2234-2246.

37. Thomas AT, Shipman FM (2018) Distilled spirit. Retrieved 2nd February, 2018.

38. Arnold J (2005) Origin and History of Beer and Brewing: From Prehistoric Times to the Beginning of Brewing Science and Technology. Cleveland, OH: BeerBooks.

39. Baliunas DO, Taylor BJ, Irving H, Roerecke M, Patra J, et al. (2009) Alcohol as a risk factor for type 2 diabetes: A systematic review and metaanalysis. Diabetes Care 32: 2123-2132.

40. Barth R (2013) The Chemistry of Beer: The Science in the Suds. John Wiley \& Sons, 2013 Aug 29.

41. Strongest beer title reclaimed with Sink the Bismarck (2018) Retrieved 2nd February, 2018.

42. Bryce E (2017) The Science Behind Beer Carbonation. Retrieved 2nd February, 2018.

43. Fergusson D, Garbutt JC, Klatsky AL, Rehm J, Saitz R, et al. (2009) Health Risks of Alcohol: 12 Health.

44. Problems Associated with Chronic Heavy Drinking (2009) Retrieved June 12, 2009.

45. Forensic Consulting (2004) Alcohol Absorption, Distribution \& Elimination. Retrieved 2nd February, 2004.

46. IARC Working Group on the Evaluation of Carcinogenic Risks to Humans (2010) IARC monographs on the evaluation of carcinogenic risks to humans. Ingested nitrate and nitrite, and cyanobacterial peptide toxins. IARC Monographs on The Evaluation of Carcinogenic Risks to Humans, p: 94.

47. Hugh J (1989) Vintage: The Story of Wine. Simon \& Schuster, pp: 11-16.

48. Levitt MD, Li R, DeMaster EG, Elson M, Furne J, et al. (1997) Use of measurements of ethanol absorption from stomach and intestine to assess human ethanol metabolism. Am J Physiol, p: 273:

49. Lorenzo $\mathrm{T}$ (2017) Traces of 6,000-year-old wine discovered in Siciliancave. Retrieved 2nd February, 2018.

50. Nelson M (2005) The barbarian's beverage: A history of beer in ancient Europe. Routledge.

51. Mokdad AH, Marks JS, Stroup DF, Gerberding JL (2000) Actual causes of death in the United States. JAMA: Journal of the American Medical Association 291: 1238-1245.

52. Nelson DE, Jarman DW, Rehm J, Greenfield TK, Rey G, et al. (2013) Alcohol-attributable cancer deaths and years of potential life lost in the United States. Am J Public Health, pp: 641-648.

53. Nutrients Review (2016) Alcohol Absorption, Metabolism and Elimination Rate. Retrieved 2nd February, 2018. 
Citation: Ayenigbara 10 (2018) Alcohol Dependence: A Major Health and Socio-Economic Problem. J Health Educ Res Dev 6: 274. doi: 10.4172/2380-5439.1000274

Page 5 of 5

54. Pattinson R (2010) European Beer Statistics. Retrieved 2nd February, 2018

55. Rothman KJ, Greenland S, Lash TL (2008) Modern epidemiology. 3rd edn., Philadelphia: Lippincott Williams \& Wilkins.

56. Rehm J, Shield KD (2014) Alcohol and mortality: global alcoholattributable deaths from cancer, liver cirrhosis and injury in 2010 Alcohol Research: Current Reviews 35: 174-183.

57. Rehm J, Mathers C, Popova S, Thavorncharoensap M, Teerawattananon $\mathrm{Y}$, et al. (2009) Global burden of disease and injury and economic cost attributable to alcohol use and alcohol use disorders. Lancet 373: 2223-2233.
58. Rudgley R (1993) The Alchemy of Culture: Intoxicants in Society. London: British Museum Press.

59. Bubba S (2018) Effects At Specific B.A.C. Levels. Retrieved 2nd February, 2018.

60. Samokhvalov AV, Irving H, Mohapatra S, Rehm J (2010) Alcohol consumption, unprovoked Seizures and epilepsy: a systematic review and meta-analysis. Epilepsia 51: 1177-1184.

61. World Health Organization (1992) The ICD-10 classification of mental and behavioural disorders: clinical descriptions and diagnostic guidelines. World Health Organization. 